nephron

Practice
Nephron 2018;140:105-110

DOI: $10.1159 / 000490500$
Received: May 22, 2018

Accepted after revision: May 29, 2018

Published online: June 26, 2018

\title{
Perioperative Acute Kidney Injury: Prevention, Early Recognition, and Supportive Measures
}

\author{
Stefano Romagnolia Zaccaria Ricci $^{\text {b }}$ Claudio Ronco c, d \\ ${ }^{a}$ Department of Anesthesiology and Intensive Care, Azienda Ospedaliero-Universitaria Careggi, Florence, Italy; \\ ${ }^{b}$ Department of Cardiology and Cardiac Surgery, Pediatric Cardiac Intensive Care Unit, Bambino Gesù Children's \\ Hospital, IRCCS, Rome, Italy; ' Department of Nephrology, Dialysis and Transplantation, San Bortolo Hospital,

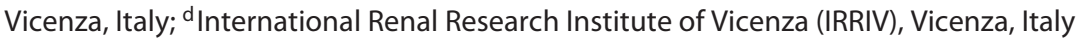

\section{Keywords}

Acute kidney injury · Perioperative · Biomarkers

\begin{abstract}
Background: Acute kidney injury (AKI) is a frequent complication of both cardiac and major non-cardiac surgery. AKI is independently associated with morbidity, mortality, and long-term adverse events including chronic kidney disease in postsurgical patients. Since specific treatment options for kidney failure are very limited, early identification, diagnosis, and renal support strategies are key steps to improve patients' outcome. Summary: According to current Kidney Disease: Improving Global Outcomes (KDIGO) guidelines, AKI diagnosis is based on 2 functional markers, serum creatinine increase and urine output decrease, that are not renal-specific and have important limitations. However, preoperative risk stratification for postoperative AKI and/or early diagnosis after surgery could be the best way to apply preventive or timely supportive therapeutic measures. Clinical prediction scores, renal functional reserve assessment, and new biomarkers of kidney stress (suppression of tumorigenicity-2, insulin-like growth factor binding protein-7, tissue in-
\end{abstract}

hibitor metalloproteinase-2) may help the clinicians to identify patients at risk of AKI and that could benefit from the application of nephroprotective bundles suggested by the KDIGO guidelines. In severe AKI patients with oligoanuria and fluid accumulation, renal replacement therapy is the only supportive measure even if mode and timing remain open to investigation. Key messages: Perioperative AKI is an important and underdiagnosed complication. Identifying patients at high risk of AKI and diagnosing AKI early are major goals. Preventive interventions are mainly based on the KDIGO guidelines and bundles. Furthermore, a personalized multidisciplinary approach should always be considered to minimize the progression of disease and the complications related to kidney damage.

(c) 2018 S. Karger AG, Basel

Contribution from the AKI and CRRT 2018 Symposium at the 23rd International Conference on Advances in Critical Care Nephrology, Manchester Grand Hyatt, San Diego, CA, USA, February 26 - March 1, 2018. This symposium was supported in part by the NIDDK funded University of Alabama at Birmingham-University of California San Diego O'Brien Center for Acute Kidney Injury Research (P30DK079337).

\section{KARGER}

(c) 2018 S. Karger AG, Basel

E-Mail karger@karger.com

www.karger.com/nef
Dr. Stefano Romagnoli

Department of Anesthesiology and Intensive Care

Azienda Ospedaliero-Universitaria Careggi, Largo Brambilla, 3

IT-50139, Florence (Italy)

E-Mail stefano.romagnoli@unifi.it 


\section{Introduction}

Complicated cardiac surgery and major non-cardiac surgery are associated with significant morbidity and mortality and strong correlation exists between the development of in-hospital complications and survival [1, 2 ]. One of these is acute kidney injury (AKI) which is independently associated with morbidity and mortality in a wide range of surgical settings [3]. Moreover, postoperative AKI is associated with long-term adverse events including chronic kidney disease and late mortality. Furthermore, even in cases of apparent recovery of renal function at hospital discharge, persistent decrease of glomerular filtration rate (GFR) with respect to preoperative level has been described [4]. Approximately $30-40 \%$ of all cases of AKI occur after surgery and postoperative AKI incidence has been described in the range between 18 and 47\% [5]. Noteworthy, early identification, diagnosis, and renal support strategies are key steps since specific treatment options for kidney failure are very limited $[5,6]$.

Despite clear improvements in AKI diagnosis occurred during the last years with the elaboration and diffusion of new diagnostic criteria [7], AKI diagnosis is based on 2 functional markers that are not renal-specific and have important limitations that may lead to late or even missed diagnosis: serum creatinine (SCr) and urine output (UO) [8]. Oliguria is neither sensitive nor specific and can occur after renal injury but also reflect an adaptive physiological response to both intracellular dehydration and hypovolemia [9], frequently occurring during and after surgery. Moreover, SCr increase may not be detected in case of fluid accumulation and/or sarcopenia leading to dilution and reduced creatine release, respectively [8]. These limitations led to explore new perioperative markers of kidney dysfunction that could allow the clinician to identify earlier the syndrome. Therefore, the identification of patients at higher risk of perioperative AKI (risk stratification) or soon after surgery (Fig. 1) could be the best way to apply preventive or early supportive therapeutic measures.

\section{Patients Identification before Surgery: Risk Stratification}

\section{Clinical Prediction Scores}

Preoperative assessment of AKI risk could help the clinicians to appropriately manage the perioperative phases in multiple areas of decision-making including

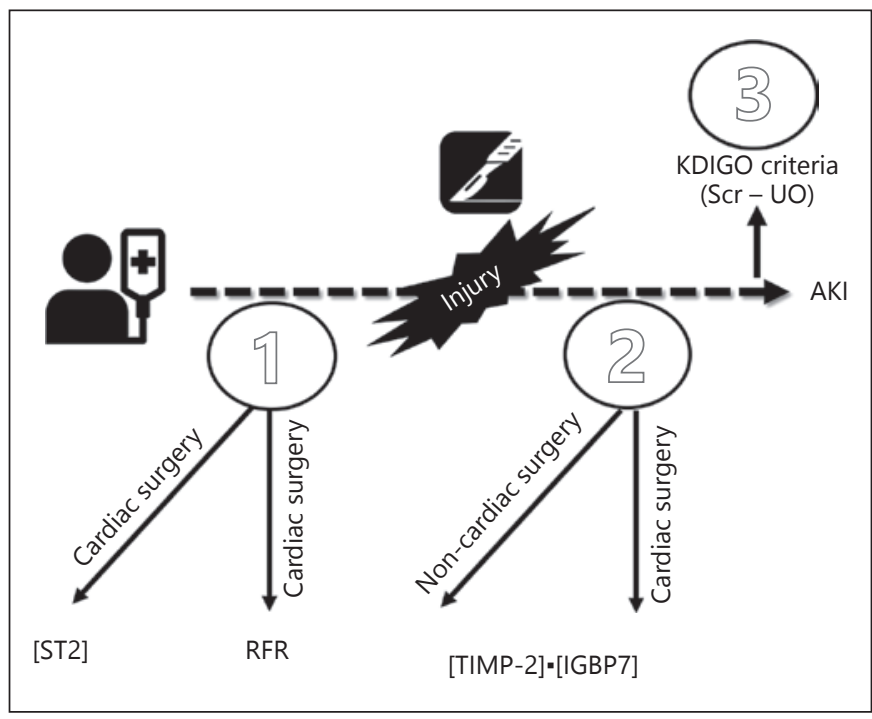

Fig. 1. Timeline of AKI during the "surgery journey". 1 Preoperative risk stratification for postoperative AKI risk (renal biomarkers or RFR); "Injury" identifies the surgical phase. 2 Diagnosis after surgery through early biomarkers of cell-cycle arrest. 3 Diagnosis according to the KDIGO criteria. The earliest is the identification of risk (1) and/or damage (2) before dysfunction (3) occurs and the greatest are the options for AKI prevention and renal protection. AKI, acute kidney injury; KDIGO, Kidney Disease: Improving Global Outcomes; SCr, serum creatinine; UO, urine output; RFR, Renal Functional Reserve; ST2, suppression of tumorigenicity-2; TIMP-2, tissue inhibitor metalloproteinase-2; IGFBP7, insulinlike growth factor binding protein 7 .

the timing of surgery (e.g., delay of cardiac surgery after the contrast media administration), appropriate intraoperative hemodynamic monitoring and management, and earlier postoperative interventions [10]. Common patients' related risk factors include chronic vascular disease, chronic kidney disease, arterial hypertension, cardiac failure, and diabetes, all of which are strongly associated with postoperative AKI [11]. In addition, AKI occurrence is also surgery related. Cardiac surgery has an AKI incidence as high as 30\% [6]. Patients' clinical characteristics and procedural-related factors favoring AKI in cardiac surgery are listed in Table 1 . Among them cardiopulmonary bypass is a principal contributor $[6,12$, 13]. In vascular and cardiac surgery, aortic cross-clamping may predispose to AKI by both abolition of arterial flow and embolization [13]. Several risk stratification systems exist for cardiac surgery patients but the best validated scores predict severe AKI requiring dialysis $[14,15]$ and new studies are needed to validate scores to predict less severe AKI after cardiac surgery [16]. On the other side, non-cardiac surgery has received much less 
Table 1. Risk factors for AKI in cardiac surgery [13]

\begin{tabular}{lll}
\hline Preoperative & Intraoperative & Postoperative \\
\hline Advanced age & Complex surgery & Vasopressor exposure \\
Gender, female & CPB & Inotrope exposure \\
Hypertension & Low HCT in CPB & Diuretic exposure \\
Hyperlipidemia & Aortic cross-clamp time & Blood transfusion \\
Chronic kidney disease & Hypoperfusion & Anemia \\
Liver disease & Hypovolemia & Hypovolemia \\
Peripheral vascular disease & Venous congestion & Venous congestion \\
Previous stroke & Emboli & Cardiogenic shock \\
Smoking history & Inotropes exposure & \\
Diabetes & & \\
Anemia & & \\
\hline
\end{tabular}

$\mathrm{CPB}$, cardiopulmonary bypass; HCT, hematocrit.

attention and most of the predictive scores predict AKI requiring renal replacement therapy (RRT) following liver transplantation or liver surgery [17]. Kheterpal et al. [18] developed a system for non-cardiac surgery for predicting AKI. Eleven independent indicators have been identified (Table 2) but a major limitation of the system is that AKI definition was based on postoperative increase in SCr of $>2 \mathrm{mg} / \mathrm{dL}$ or the need for dialysis within 30 days of operation that are very far from the new Kidney Disease: Improving Global Outcomes (KDIGO) criteria.

\section{Renal Functional Reserve}

Accurate determination of GFR is an essential component of the assessment of kidney function. Nonetheless, measurement of GFR in clinical practice is unpractical. Urine collection over $24 \mathrm{~h}$ with measurement of the excretion of SCr has been accepted as the best clinical approach to determine GFR [19]. However, one of the main requirements of GFR assessment is a steady state AKI stage that might often not be the case in rapidly evolving renal dysfunction [8]. GFR estimating equations (eGFR) have been developed based upon measurements of $\mathrm{SCr}$ (e.g., Modification of Diet in Renal Disease and Chronic Kidney Disease Epidemiology). These equations deliver a mean eGFR for individuals of the same age, sex, and race. SCr production and hemodilution may impair the reliability of these equations.

In order to overcome this limitation, the quantification of Renal Functional Reserve (RFR), a measure of the kidney's capacity to increase GFR by a combination of nephron recruitment and increases in renal blood flow coupled with hyperfiltration, has been proposed
Table 2. Independent predictors of AKI performed on 57,080 patients [19]

\begin{tabular}{ll}
\hline Independent predictors of AKI & $\begin{array}{l}\text { Adjusted } \\
\text { hazards } \\
\text { ratio (95\% CI) }\end{array}$ \\
\hline Intraperitoneal surgery & $3.3(2.4-4.7)$ \\
Moderate preoperative renal insufficiency & $3.2(2.8-3.7)$ \\
Mild preoperative renal insufficiency & $3.1(2.5-3.9)$ \\
Ascites & $3.0(2.2-4.0)$ \\
Active congestive heart failure & $2.0(1.4-3.0)$ \\
Emergency surgery & $1.9(1.5-2.3)$ \\
Age 56 years or older & $1.7(1.4-2.2)$ \\
Diabetes mellitus necessitating insulin therapy & $1.7(1.3-2.3)$ \\
Hypertension & $1.5(1.2-1.9)$ \\
Gender, male & $1.4(1.2-1.7)$ \\
Diabetes mellitus necessitating oral therapy & $1.3(1.0-1.7)$ \\
\hline
\end{tabular}

AKI, acute kidney injury.

[20-22]. Healthy nephrons have the ability to increase filtration rate. This physiological mechanism can be used to estimate a global potential nephron recruitment in order to stratify, before surgery, the possibility to tolerate renal injuries and additional loads. It has been estimated that RFR physiologically accounts for over a $30 \%$ increase in GFR $[20,21]$. Such determinations are easily made by determining the difference between GFR measured before and 1-2 $\mathrm{h}$ after eating a protein meal [20]. The RFR was recently used as a predictive test in 110 cardiac surgery patients with normal resting GFR. An RFR $<30 \mathrm{~mL} / \mathrm{min} / 1.73 \mathrm{~m}^{2}$ was found in 79 patients (71.8\%). AKI occurred in $13.6 \%$ of the patients and pre- 
Table 3. The KDIGO "bundles"

Discontinuation of all nephrotoxic agents (when possible).

Ensuring volume status and perfusion pressure.

Considering functional hemodynamic monitoring.

Monitoring SCr and UO.

Avoiding hyperglycemia.

Considering alternatives to radiocontrast procedures.

operative RFR was lower in patients who developed AKI $(p<0.001)$ and predicted AKI with an area under the receiver operating characteristic curve of 0.83 (95\% CI 0.70-0.96). Moreover, patients with preoperative RFRs $\leq 15 \mathrm{~mL} / \mathrm{min} / 1.73 \mathrm{~m}^{2}$ were 11.8 times more likely to develop AKI $(p<0.001)$. Interestingly, preoperative values of cell cycle arrest biomarkers, urine tissue inhibitor metalloproteinase-2 (TIMP-2), insulin-like growth factor binding protein-7 (IGFBP-7; see below), did not differ between AKI and non-AKI patients $(p=$ $0.70)$.

\section{Preoperative Biomarker}

The suppression of tumorigenicity-2 (ST2) biomarker is a cardiac stress protein belonging to the interleukin-1 receptor family. Very recently, Lobdell et al. [23] used ST2 to predict AKI before isolated coronary artery bypass graft surgery collecting data from 1,690 patients. The authors found that $35 \%$ of the patients developed AKI. Patients in the highest tercile of ST2 had twice the odds of developing stage 2 or stage 3 AKI compared with stage 1. Lobdell et al.'s study [23] is the first demonstration of a biomarker as a potential predictor of AKI among patients in a large cardiac surgical cohort.

\section{Early Diagnosis and Supportive Measures in the Postoperative Phase}

In order to overcome some of the limitations of SCr and $\mathrm{UO}$, a variety of functional and damage biomarkers have been identified and validated in humans as tools to diagnose subclinical AKI earlier than traditional tests [24]. Among them, the association of TIMP-2 and IGFBP-7 biomarkers involved in G1 cell cycle arrest has been demonstrated to predict Major Adverse Kidney Events (death, dialysis or persistent renal dysfunction) within 30 days (MAKE30) with high sensitivity and specificity when above $0.3 \mathrm{ng} / \mathrm{mL} / 1,000$ in urine
[25] in critically ill patients upon intensive care unit admission.

These biomarkers have been recently used for early identification of high risk patients and subsequent application of "KDIGO bundles" (Table 3) [7] in 2 studies in cardiac and non-cardiac surgery respectively. In this context, the importance of intraoperative arterial blood pressure was recently confirmed: even few minutes of hypotension (below 55-65 mm Hg of mean arterial pressure) are associated with increased risk of AKI and myocardial injury after non-cardiac surgery [26-28]. Meersch et al. [29] studied the effect of KDIGO bundles in patients at high risk of AKI (those with postoperative urine levels of IGFBP7 and TIMP-2 $>0.3 \mathrm{ng} / \mathrm{mL} / 1,000)$ who had undergone cardiac surgery. The authors found that rates of AKI were significantly lower in patients who received the bundled intervention than in patients who received standard care (55.1 vs. $71.7 \%$; $p=0.004)$. Moreover, in the intervention group significantly lower rates of moderate and severe AKI were observed compared to the control group (29.7 vs. $44.9 \% ; p=0.009$ ). Similarly, Göcze et al. [30] applied a similar protocol in high-risk non-cardiac surgery patients. In patients with biomarkers values between 0.3 and 2.0 , they were able to show a significantly reduced incidence of AKI 13 of 48 (27.1\%) in the intervention group compared to control 24 of $50(48.0 \%, p=0.03)$. Incidence of moderate and severe AKI $(p=0.04)$, incidence of creatinine increase $>25 \%$ of baseline value $(p=0.01)$, length of intensive care unit, and hospital stay $(p=0.04)$ were significantly lower in the intervention group. On the contrary, there were no significant differences regarding RRT, in-hospital mortality, or MAKE at hospital discharge.

\section{Renal Replacement Therapy}

In severe AKI, especially in case of fluid accumulation in hemodynamically unstable anuric patients, RRT is the only supportive measure. The best RRT mode, intermittent vs. continuous vs. hybrid techniques, the optimal prescription and timing of initiation/discontinuation, remain open to investigation. Current KDIGO guidelines recommend initiation of RRT emergently when life-threatening changes in fluid, electrolyte, and acid-base balance exist and to consider, in all other potential indications, the broader clinical context rather than single marker threshold alone [7]. The recent Acute Dialysis Quality Initiative on "Patient Selection and Timing of Continuous RRT" suggested that the de- 
cision to initiate, maintain, and discontinue continuous RRT should be individualized. The personalized approach should be based on the demand-capacity concept [31].

\section{Final Considerations}

Perioperative AKI is an important and underdiagnosed complication with high associated morbidity and mortality. Identifying patients at high risk of AKI and diagnosing AKI early are major goals since treatment op- portunity are limited and early supportive measures may slow the disease progression.

Renoprotective interventions are mainly based on the KDIGO guidelines and bundles but a personalized and multidisciplinary approach to the care of each patient in the perioperative setting may help to minimize the risk of developing renal complications related to anesthesia and surgery.

\section{Disclosure Statement}

The authors have no conflicts of interest to declare.

\section{References}

1 Pearse RM, Moreno RP, Bauer P, Pelosi P, Metnitz P, Spies C, Vallet B, Vincent JL, Hoeft A, Rhodes A; European Surgical Outcomes Study (EuSOS) group for the Trials groups of the European Society of Intensive Care Medicine and the European Society of Anaesthesiology: Mortality after surgery in Europe: a 7 day cohort study. Lancet 2012;380:10591065.

2 Vives M, Wijeysundera D, Marczin N, Monedero P, Rao V: Cardiac surgery-associated acute kidney injury. J Anesth 2014;18: 637-645.

3 Uchino S, Kellum JA, Bellomo R, Doig GS, Morimatsu H, Morgera S, Schetz M, Tan I, Bouman C, Macedo E, Gibney N, Tolwani A, Ronco C; Beginning and Ending Supportive Therapy for the Kidney (BEST Kidney) Investigators: Acute renal failure in critically ill patients: a multinational, multicenter study. JAMA 2005; 17:813-818.

4 O'Connor ME, Kirwan CJ, Pearse RM, Prowle JR: Incidence and associations of acute kidney injury after major abdominal surgery. Intensive Care Med 2016;42:521-530.

5 Meersch M, Schmidt C, Zarbock A: Perioperative acute kidney injury: an under-recognized problem. Anesth Analg 2017;125:12231232.

6 Romagnoli S, Ricci Z, Ronco C: Therapy of acute kidney injury in the perioperative setting. Curr Opin Anaesthesiol 2017;30:92-99.

7 Kidney Disease Improving Global Outcomes: KDIGO clinical practice guideline for anemia in chronic kidney disease. Kidney Int Suppl 2012;2.

8 Ricci Z, Romagnoli S: Acute kidney injury: diagnosis and classification in adults and children. Contrib Nephrol 2018;193:1-12.

9 Prowle JR, Liu Y-L, Licari E, Bagshaw SM, Egi M, Haase M, Haase-Fielitz A, Kellum JA, Cruz D, Ronco C, Tsutsui K, Uchino S, Bellomo R: Oliguria as predictive biomarker of acute kidney injury in critically ill patients. Crit Care 2011;15:R172.
10 Engelman DT, Kellum JA: The difficulty of predicting postoperative acute kidney injury from preoperative clinical data. J Thorac Cardiovasc Surg 2018;1-2.

11 Golden D, Corbett J, Forni LG: Peri-operative renal dysfunction: Prevention and management. Anaesthesia 2016;71:51-57.

12 O’Neal JB, Shaw AD, Billings FT: Acute kidney injury following cardiac surgery: current understanding and future directions. Crit Care 2016;20:187.

13 Romagnoli S, Ricci Z: Postoperative acute kidney injury. Minerva Anestesiol 2015;81: 684-696.

14 Thakar CV: A clinical score to predict acute renal failure after cardiac surgery. J Am Soc Nephrol 2004;16:162-168.

15 Mehta RH, Grab JD, O'Brien SM, Bridges CR, Gammie JS, Haan CK, Ferguson TB, Peterson ED; Society of Thoracic Surgeons National Cardiac Surgery Database Investigators: Bedside tool for predicting the risk of postoperative dialysis in patients undergoing cardiac surgery. Circulation 2006;114:22082216.

16 Pozzoli S, Simonini M, Manunta P: Predicting acute kidney injury: current status and future challenges. J Nephrol 2017;31:209-223.

17 Wilson T, Quan S, Cheema K, Zarnke K, Quinn R, de Koning L, Dixon E, Pannu N, James MT: Risk prediction models for acute kidney injury following major noncardiac surgery: systematic review. Nephrol Dial Transplant 2016;31:231-240.

18 Kheterpal S, Tremper KK, Heung M, et al: Development and validation of an acute kidney injury risk Index for patients undergoing general surgery: results from a national data set. Anesthesiology 2009;110:505-515.

19 Rebholz CM, Inker LA, Chen Y, Liang M, Foster MC, Eckfeldt JH, Kimmel PL, Vasan RS, Feldman HI, Sarnak MJ, Hsu CY, Levey AS, Coresh J; Chronic Kidney Disease Biomarkers Consortium: Risk of ESRD and mortality associated with change in filtra- tion markers. Am J Kidney Dis 2017;70: 551-560.

20 Ronco C, Bellomo R, Kellum J: Understanding renal functional reserve. Intensive Care Med 2017;43:917-920.

21 Husain-Syed F, Ferrari F, Sharma A, Danesi TH, Bezerra P, Lopez-Giacoman S, Samoni S, de Cal M, Corradi V, Virzì GM, De Rosa S, Muciño Bermejo MJ, Estremadoyro C, Villa G, Zaragoza JJ, Caprara C, Brocca A, Birk HW, Walmrath HD, Seeger W, Nalesso F, Zanella M, Brendolan A, Giavarina D, Salvador L, Bellomo R, Rosner MH, Kellum JA, Ronco C: Preoperative renal functional reserve predicts risk of acute kidney injury after cardiac operation. Ann Thorac Surg 2018; 105:1094-1101.

22 Sharma A, Mucino MJ, Ronco C: Renal functional reserve and renal recovery after acute kidney injury. Nephron Clin Pract 2014;127: 94-100.

23 Lobdell K, Parker DM, Likosky DS, Rezaee M, von BallmoosMW, Alam SS, Owens S, Thiessen-Philbrook H, MacKenzie T, Brown JR: Preoperative serum ST2 level predicts acute kidney injury after adult cardiac surgery. J Thorac Cardiovasc Surg 2018;11:pii.

24 Pickering JW, Endre ZH: Bench to bedside: the next steps for biomarkers in acute kidney injury. Am J Physiol Renal Physiol 2016; 311:F717-F721.

25 Kashani K, Al-Khafaji A, Ardiles T, Artigas A, Bagshaw SM, Bell M, Bihorac A, Birkhahn R, Cely CM, Chawla LS, Davison DL, Feldkamp T, Forni LG, Gong MN, Gunnerson KJ, Haase M, Hackett J, Honore PM, Hoste EA, JoannesBoyau O, Joannidis M, Kim P, Koyner JL, Laskowitz DT, Lissauer ME, Marx G, McCullough PA, Mullaney S, Ostermann M, Rimmelé T, Shapiro NI, Shaw AD, Shi J, Sprague AM, Vincent JL, Vinsonneau C, Wagner L, Walker MG, Wilkerson RG, Zacharowski K, Kellum JA: Discovery and validation of cell cycle arrest biomarkers in human acute kidney injury. Crit Care 2013;17:R25. 
26 Walsh M, Devereaux PJ, Garg AX, Kurz A, Turan A, Rodseth RN, Cywinski J, Thabane L, Sessler DI. Relationship between intraoperative mean arterial pressure and clinical outcomes after noncardiac surgery: toward an empirical definition of hypotension. Anesthesiology 2013;119:507-515.

27 Sun LY, Wijeysundera DN, Tait GA, Beattie WS: Association of intraoperative hypotension with acute kidney injury after elective noncardiac surgery. Anesthesiology 2015; 123:515-523.
28 Salmasi V, Maheshwari K, Yang D, Mascha EJ, Singh A, Sessler DI, Kurz A: Relationship between intraoperative hypotension, defined by either reduction from baseline or absolute thresholds, and acute kidney and myocardial injury after noncardiac surgery. Anesthesiology 2017;126:47-65.

29 Meersch M, Schmidt C, Hoffmeier A, Van Aken H, Wempe C, Gerss J, Zarbock A: Prevention of cardiac surgery-associated AKI by implementing the KDIGO guidelines in high risk patients identified by biomarkers: the PrevAKI randomized controlled trial. Intensive Care Med 2017;43:1551-1561.
30 Göcze I, Jauch D, Götz M, Kennedy P, Jung B, Zeman F, Gnewuch C, Graf BM, Gnann W, Banas B, Bein T, Schlitt HJ, Bergler T: Biomarker-guided Intervention to prevent acute kidney injury after major surgery: the prospective randomized BigpAK study. Ann Surg 2018;267:1013-1020.

31 Ostermann M, Joannidis M, Pani A, Floris M, De Rosa S, Kellum J, et al: Patient selection and timing of continuous renal replacement therapy. Blood Purif 2016;15261:224237. 